Journal of Measurements, Electronics, Communications, and Systems (2015) CS0115-02

www.jmecs.org/volla

\title{
Analysis and Simulation of Wavelet Carrier Modulation with Clipping Techniques in Mobile WiMAX
}

\author{
M. M. Kusuma ${ }^{1}$, R. P. Astuti ${ }^{1}$, and D. Arseno ${ }^{1}$ \\ ${ }^{1}$ School of Electrical Engineering, Telkom University, Bandung, 40287, Indonesia
}

\begin{abstract}
The implementation of OFDM results in relatively high Peak-to-Average Power Ratio (PAPR) due to IFFT process to generate orthogonal subcarriers. A number of studies have attempted to apply various techniques to minimize PAPR by applying the Wavelet transform as a substitution for Fourier transform. Another technique used to reduce the PAPR is clipping. In this journal, writer tried to apply the clipping technique on the Wavelet based OFDM in mobile WiMAX standard to obtain better performance. The results, Wavelet based OFDM has better immunity to noise and more resistant to Doppler shift than Fourier based OFDM. Sym 7 with Classical clipping and CR 1.2 can be applied on wavelet-based OFDM in mobile WiMAX.
\end{abstract}

Keywords: Clipping; Fourier; Mobile WiMAX; OFDM; PAPR; Wavelet

\section{Introduction}

One of the techniques used to minimize frequency selective fading is an Orthogonal Frequency Division Multiplexing (OFDM) [1]. OFDM will change channel condition from frequency selective fading into flat fading. But the implementation of OFDM results in high Peak-toAverage Power Ratio (PAPR) [1]. High PAPR, generated after IFFT process, will increases the complexity of the analog - to - digital and digital to - analog converter and reduces the efficiency of the radio - frequency (RF) power amplifier [1-2].

Recently the Wavelet Transform has also been proposed as a possible transform to generate the sub channels in a multicarrier system [3]. In addition, Wavelet based OFDM does not require Cyclic Prefix (CP) [3-4], thus increasing the spectral efficiency, does not produce ripples, reduces complexity and leads to a better symbol rate, so there is no wastage of power for redundancy [4].

Besides that, there are several techniques that have been proposed by reference to reduce the PAPR such as clipping technique, block coding, selective mapping and tone reservation [1-2]. Among these techniques, the clipping technique is the simplest solution technique. Signal amplitude exceeds a desired threshold can be cut to the desired power level, so that no high PAPR [5].

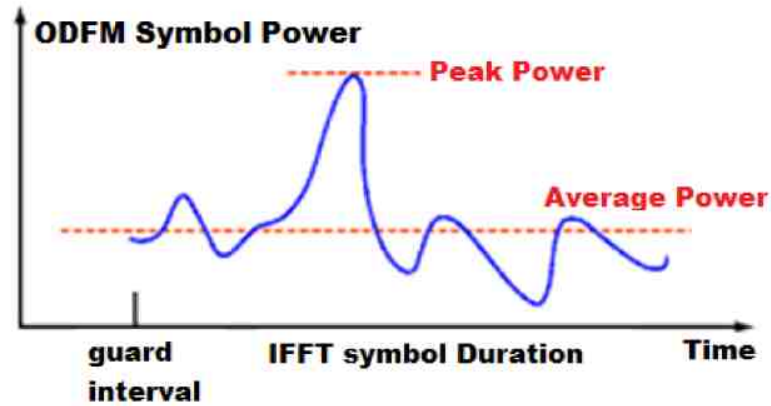

Fig. 1. PAPR
In this journal, clipping technique will be applied with the Wavelet based OFDM with the Wavelet based OFDM in mobile WiMAX standard. The purposes are to analyze the performances of wavelet based OFDM with any wavelet filters and any clipping techniques then comparing with Fourier based.

\section{OFDM, Wavelet, PAPR And Clipping \\ 2.1 Orthogonal Frequency Division Multiplexing (OFDM)}

OFDM is a modulation technique that uses multiple carrier frequencies (multicarrier) are mutually orthogonal to each other, so between adjacent subcarriers can be made without any intercarrier interference (ICI) effects.

In the communication system, the orthogonal signals occur if these each signals stand alone without interfere each other. Two periodic signals are orthogonal when the integral of their product over one period is equal to zero $[2,6]$.

$$
\int_{a}^{b} \varphi_{p}(t) \varphi_{q} *(t) d t=0
$$

Conventional OFDM used Fourier transform to generate the orthogonal subcarriers. The Fourier converts signals from the time domain to the frequency domain. On the transmitter side the OFDM using IFFT while at the receiver side using the FFT.

$$
\begin{aligned}
& \text { IFFT: } x(n)=\frac{1}{N} \sum_{n=0}^{N-1} x(k) e^{j 2 \pi \frac{n k}{N}} \\
& \text { FFT: } x(k)=\sum_{n=0}^{N-1} x(n) e^{-j 2 \pi \frac{n k}{N}}
\end{aligned}
$$

where:

$\mathrm{N} \quad=$ IFFT ponts (subcarrier total)

$\mathrm{x}(\mathrm{k}) \quad=$ signal in frequency domain

$\mathrm{x}(\mathrm{n}) \quad=$ signal in tine domain 
Kusuma et al. / Journal of Measurements, Electronics, Communications, and Systems (2015) CS0115-02

\subsection{Wavelet}

Wavelet is a short wave (small wave) which energy concentrated in a time interval to provide transient analysis capabilities, un-stationer or timevarying phenomena. Characteristics of wavelets is a short oscillatory, translational (shift), and dilation (scale).

There are two types of wavelet transform are Continue Wavelet Transform (CWT) and Discrete Wavelet Transform (DWT). The wavelet transform that used in the simulation is DWT. DWT is used to transform into discrete data.

Each wavelet filter has 2 High Pass Filter (Hi_R and Hi_D) and 2 Low Pass Filter (Lo_R and Lo_D) that filter size determined by orde and coefficient filter. IDWT process use Lo_R dan Hi_R filter. The input of detail coefficients are 16 QAM signal mapping $(\mathrm{x})$ while the approximation coefficients are padding zero. After up-sampling, approximation coefficients convoluted with Low Pass Filter (Lo_R). while detail coefficients convoluted with High Pass Filter (Hi_R). Then summed both.

DWT process use Lo_D dan Hi_D filter. That filter reverse from Lo_R and Hi R filter in IDWT. To obtain the approximation coefficients, the signal (s) is convoluted with Low Pass Filter (Lo_D) then downsampling. The approximation coefficients contain zero padding. Meanwhile, to obtain the detail coefficients, the signal (s) is convoluted with High Pass Filter (Hi_D) then downsampling. Detail coefficients contain the received signal $(\mathrm{y})$.

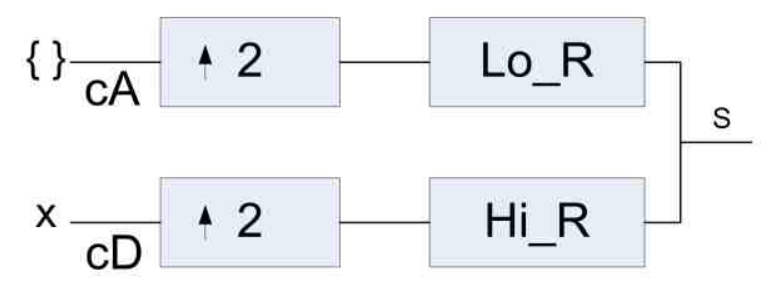

Fig. 2. IDWT Process

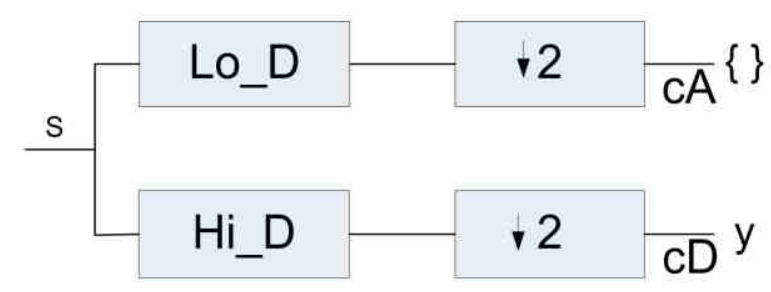

Fig. 3. DWT Process

\subsection{Peak to Average Power Ratio (PAPR)}

PAPR is the ratio between peak power of the signal with average power [5]. The higher PAPR causes signal quality decreased.

$$
P A P R=\frac{P_{\max }}{P_{\text {avg }}}=\frac{\max \left|s(t)^{2}\right|}{E\left[\left|s^{2}(t)\right|\right]}
$$



\subsection{Clipping}

The simplest way to reduce PAPR is cut peak signal amplitude into a maximum level required. Although be a simple solution, clipping technique will be able to damage the signal so that it will change the shape and impact on bit error detection at the receiver side.

Clipping technique used in this journal are the classical clipping and smooth clipping with Eq. (5) and Eq. (6).

\section{Classical clipping}

$$
f(r)=\left\{\begin{array}{l}
r, r \leq A \\
A, r>A
\end{array}\right.
$$

\section{Smooth clipping}

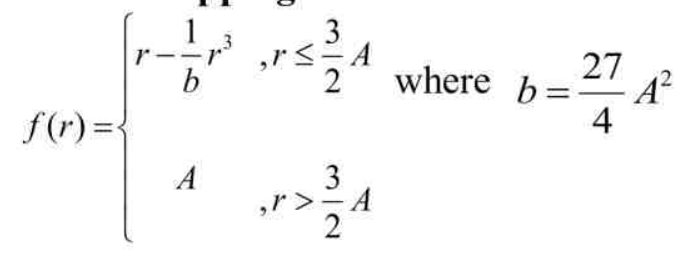

Another parameter that characterizes the clipping performance is clipping ratio that is given by Eq. (7), where $\sigma$ is the rms level of the OFDM signals. In this journal using $\mathrm{CR}=1,1.2$, and 1.4.

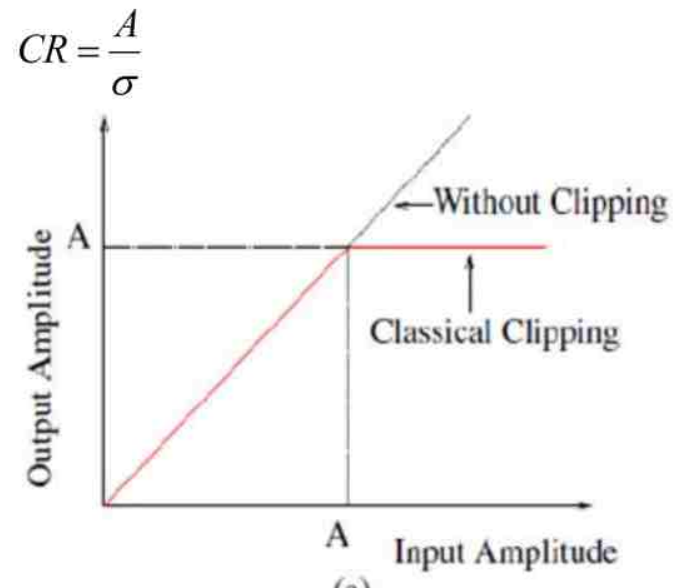

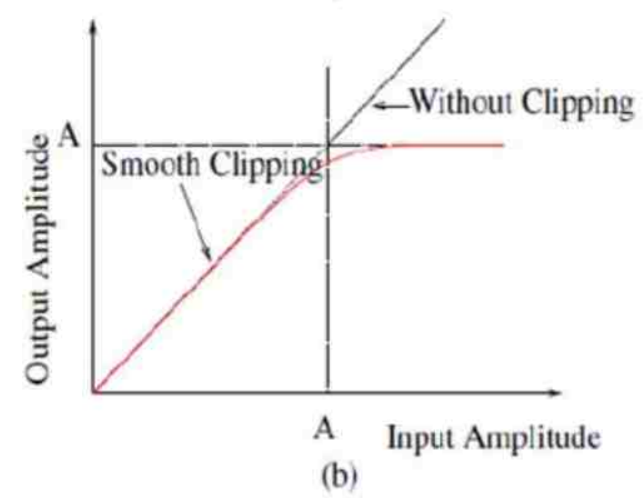

Fig. 4. (a) Classical Clipping (b) Smooth Clipping $[1,7]$ 
Kusuma et al. / Journal of Measurements, Electronics, Communications, and Systems (2015) CS0115-02

\section{Simulation and Performance Parameter}

The analysis observe the downlink direction carrier frequency of $3.5 \mathrm{GHz}$ communication with mobile WiMAX standard. Simulations use different wavelet filters and any clipping techniques to find out which has higher performance than Fourier based.

In simulation, random data will be processed by convolutional coding with coderate $1 / 2$ and interleaver before mapped by 16QAM mapper. Then, signal will be processed with STBC coder with Alamouti $2 \times 2$ algorithm. After that, incoming signals passed IFFT/IDWT block to generate orthogonal subcarriers.

Last, signal will be clipped before transmitted. Transmitted signal will be passed on channel AWGN and Rayleigh distribution. The system was tested outdoors (outdoor) with user speed $3 \mathrm{~km} / \mathrm{h}$ and $30 \mathrm{~km} / \mathrm{h}$ in pedestrian environment low delay spread. Performance parameters were observed graphs $\mathrm{CCDF}$ and BER against Eb/No.

\subsection{Simulation Parameter}

System simulation has OFDM parameters as shown in Table 1.

\subsection{Block Diagram System}

System will be simulated as block diagrams at Figure 5 and Figure 6 bellow.

\subsection{Cumulative Complementary Distribution Function}

PAPR described statistically by using Cumulative Complementary Distribution Function $(\mathrm{CCDF})$, where $\mathrm{CCDF}=1-\mathrm{CDF} . \mathrm{CDF}$ is a cumulative value of $\operatorname{PAPR} F(z)=1-\exp (-z)$. PAPR is calculated after the clipping process $[1,7]$. CCDF:

$$
\begin{aligned}
P(P A P R>z) & =1-P(P A P R \leq z) \\
& =1-F(z)=1-(1-\exp (-z))
\end{aligned}
$$

\subsection{Bit Error Rate}

Bit Error Rate (BER) is the most important parameter in determining the quality of a system. The higher value indicates the BER performance of the system is getting worse, because the information received at the receiver side through many changes during transmission.

$$
B E R=\frac{\text { BitError }}{\text { TotalBit }}
$$

Simulation repeat 15 times iteration to get result that closer to the truth. The number of minimum transmit bit to get specific BER can be calculate by Eq. (10) [5]:

$$
B=\frac{10}{B E R}
$$

Table 1. Simulation Parameter

\begin{tabular}{|l|l|}
\hline Parameter & Mobile WIMAX \\
\hline FFT point & 512 \\
\hline Cyclic prefix & $1 / 4$ \\
\hline Modulation & 16QAM \\
\hline Interleaver & Row: 128, column: flexible \\
\hline $\begin{array}{l}\text { Convolutional } \\
\text { Code }\end{array}$ & $\begin{array}{l}\text { Inner-code }\left(\mathrm{g}_{0}=133_{8}, \mathrm{~g}_{1}=171_{8},\right. \\
\mathrm{K}=7)\end{array}$ \\
\hline Clipping Type & $\begin{array}{l}\text { Classical Clipping and } \\
\text { Smooth Clipping }\end{array}$ \\
\hline Clipping Ratio & CR=1, CR=1.2, and CR=1.4 \\
\hline Wavelet Filter & $\begin{array}{l}\text { Haar, Daubechies, Coiflets, } \\
\text { Symlets, Biorthogonal, and } \\
\text { Reverse Biorthogonal. }\end{array}$ \\
\hline User velocity & $3 \mathrm{~km} / \mathrm{h}$ and $30 \mathrm{~km} / \mathrm{h}$ \\
\hline
\end{tabular}

\section{Wavelet Carrier Modulation with Clipping Techniques in Mobile WiMAX 4.1 Comparison BER of FFT and Wavelet OFDM}

Wavelet daubechies (db) has $\mathrm{N}$ orde write as $\mathrm{dbN}$. For $\mathrm{N}=1$ called Haar and $\mathrm{N}=2,3,4, \ldots 45$. Daubechies filter coefficient equals $2 \mathrm{~N}$. A daubechies with $\mathrm{N}$ orde has vanishing moment value equals N. Vanishing moment show the ability for representing polynomial attributes to define number of wavelet filter coefficient. $\mathrm{dbN}$ are asymmetric than another wavelet family.

User velocity or Doppler shift can be calculated by Eq. (11). From Eq. (11) get $f_{d}=10 \mathrm{~Hz}$ for $3 \mathrm{~km} / \mathrm{h}$ velocity and $f_{d}=97 \mathrm{~Hz}$ for $30 \mathrm{~km} / \mathrm{h}$ velocity.

$$
f_{d}=\frac{f_{c} \cdot v}{c} \cos \theta
$$

Daubechies wavelet based OFDM is resistant to Doppler shift if compared with Fourier based. BER daubechies wavelet based OFDM have $4.106 \%$ degradation caused Doppler shift. That value is better than Fourier based, with $12.063 \%$ degradation. 
Journal of Measurements, Electronics, Communications, and Systems (2015) CS0115-02

www.jmecs.org/volla

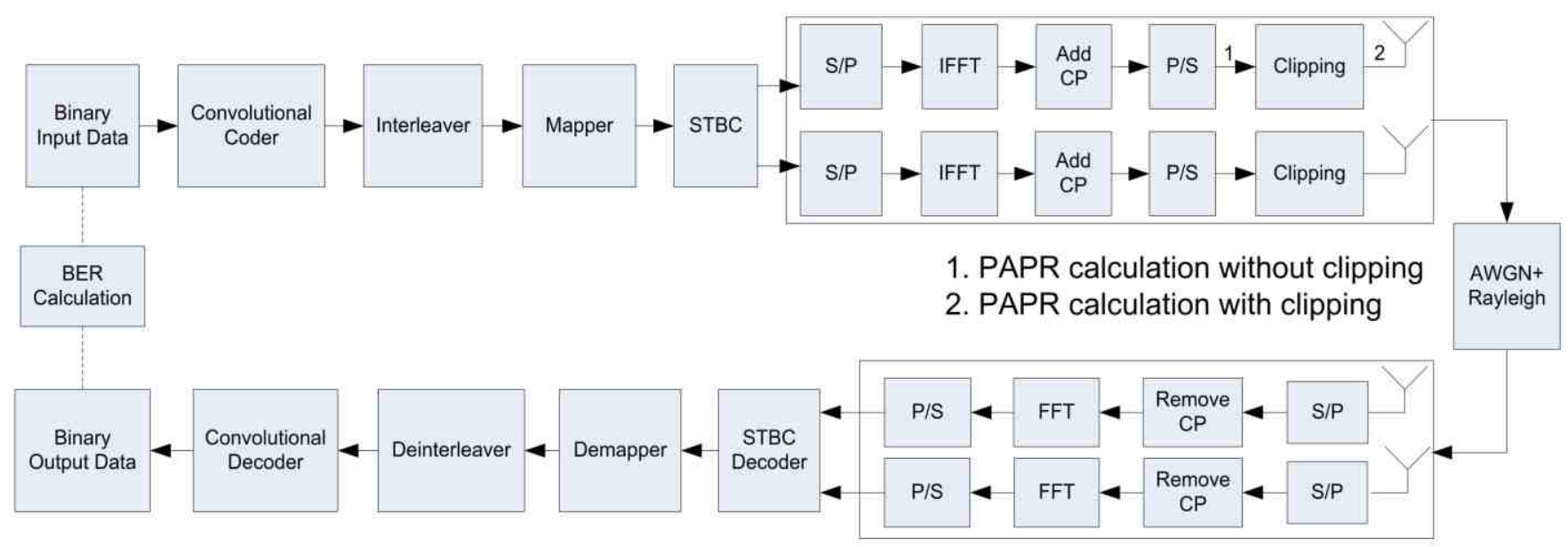

Fig. 5. 2x2 MIMO Fourier OFDM with Clipping

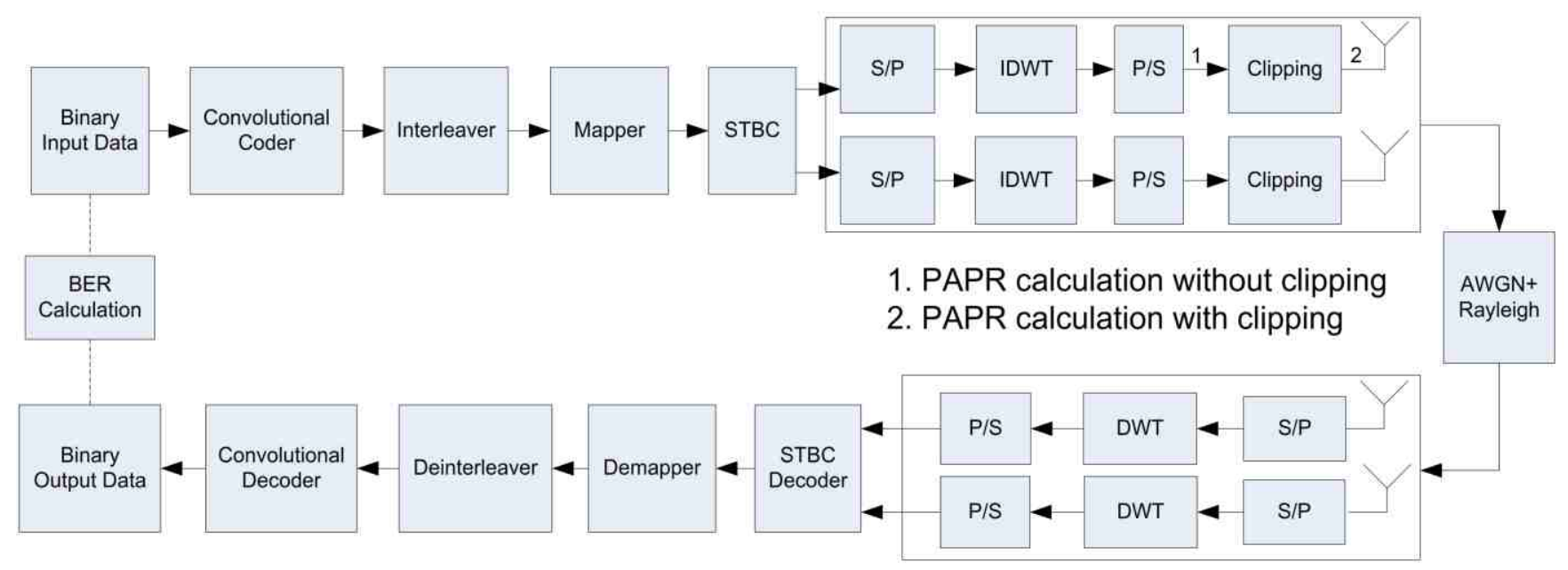

Fig. 6. 2x2 MIMO Wavelet OFDM with Clipping

Symlet (sym) has $\mathrm{N}$ orde write as symN where $\mathrm{N}=2,3,4, \ldots 45$. Symlet wavelet filter coefficient same as daubechies equals $2 \mathrm{~N}$. Symlet is a modification daubechies filter but more symmetric. Symlet is more resistant to Doppler shift than daubechies, because its average $2.101 \%$ degradation.

Coiflets (Coif) has $\mathrm{N}$ orde write as CoifN, where $\mathrm{N}=1, \ldots ., 5$. CoifN filter coefficient equals with $3 \mathrm{dbN}$, example coif5 equals $3 \mathrm{x}$ dB5 filter coefficient. CoifN is more symmetric than debauchies. BiorNr.Nd and rbioNr.Nd are also orthogonal and symmetric wavelet filter, where $\mathrm{Nr}$ and $\mathrm{Nd}$ use to define orde and number of filter coefficient. Coiflet, biorNr.Nd and rbioNr.Nd also resistant to Doppler shift, average $3.064 \%$ degradation.
For all wavelet filters, the greater $\mathrm{N}$ orde is, the worse the BER. Due to higher spectral containment between sub channels, wavelet-based OFDM is better able to overcome the effects of narrowband interference and is inherently more robust with respect to ICI than traditional Fourier filters. For detail please see Figure 7, 8, 9 and Table 2

\subsection{Comparison CCDF of FFT and Wavelet}

For PAPR performance can be reviewed with CCDF graphic at $10^{-1}$. PAPR in wavelet based OFDM always better than Fourier based OFDM. From Figure 10 and 11, Fourier has greatest PAPR around $9.316 \mathrm{~dB}$ because high PAPR generated after IFFT process. Meanwhile haar, bior1.1 and rbio1.1 smallest around $2.68 \mathrm{~dB}$, impacted to BER for haar wavelet based OFDM better than Fourier based. 
Journal of Measurements, Electronics, Communications, and Systems (2015) CS0115-02 www.jmecs.org/volla

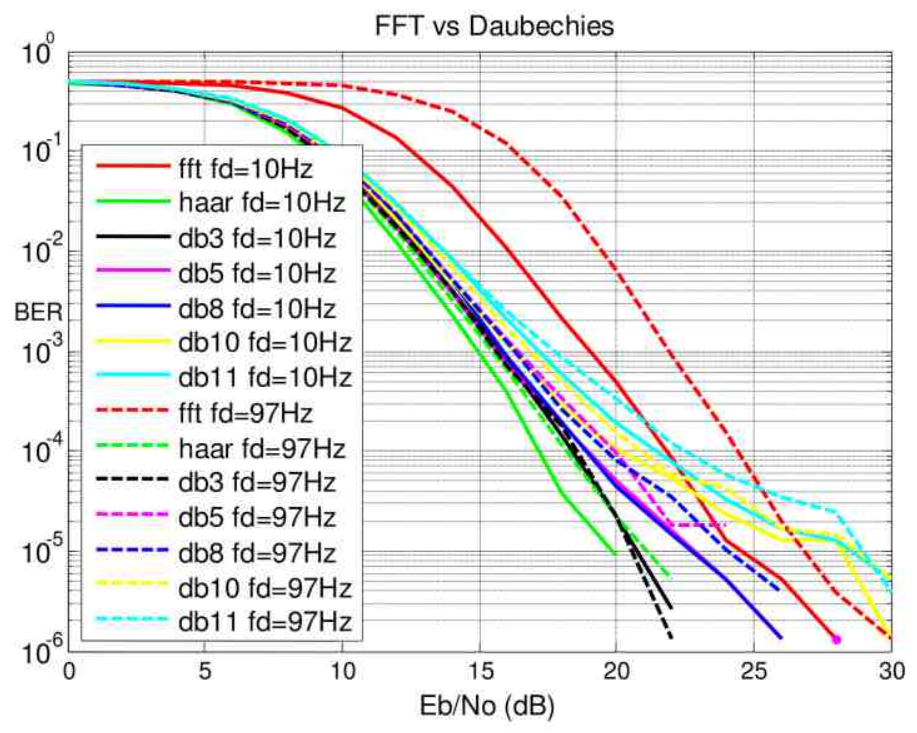

Fig. 7. BER FFT vs Daubechies

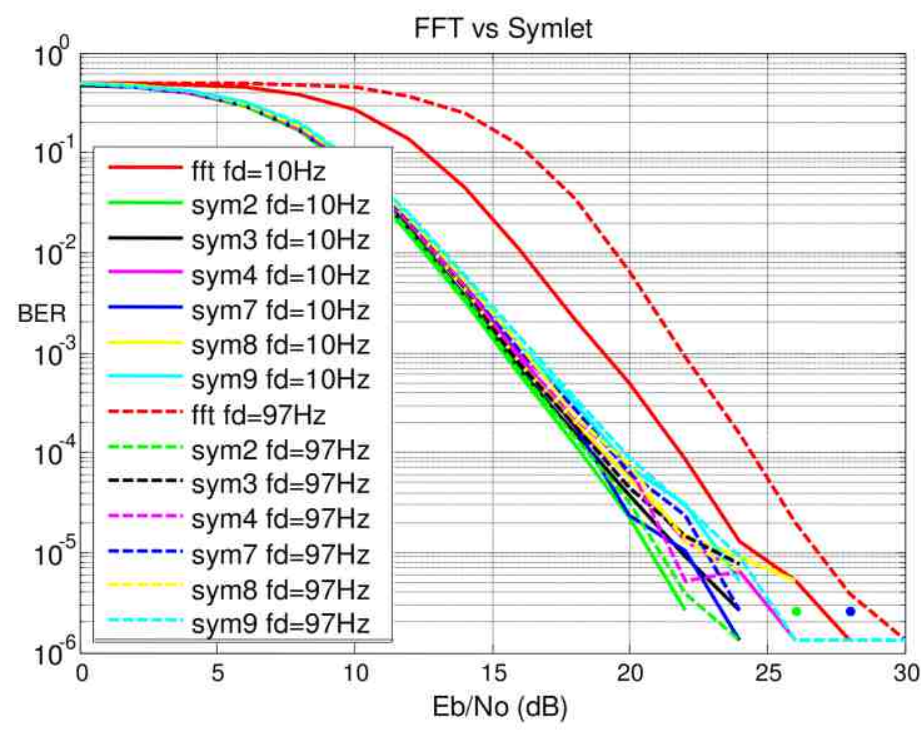

Fig. 8. BER FFT vs Symlet

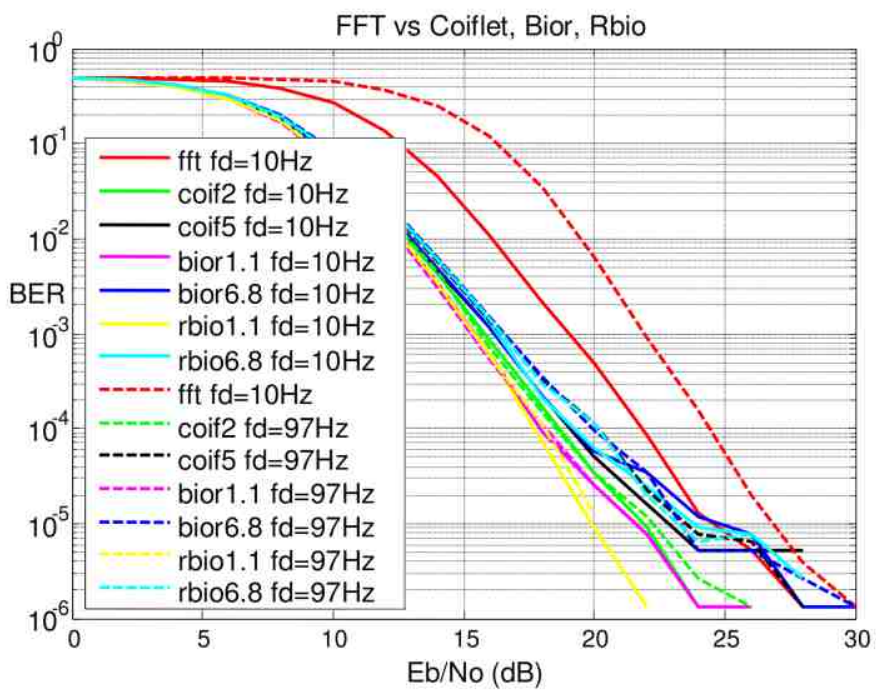

Fig. 9. BER FFT vs Coiflet, Biorthogonal and Reverse Biorthognal

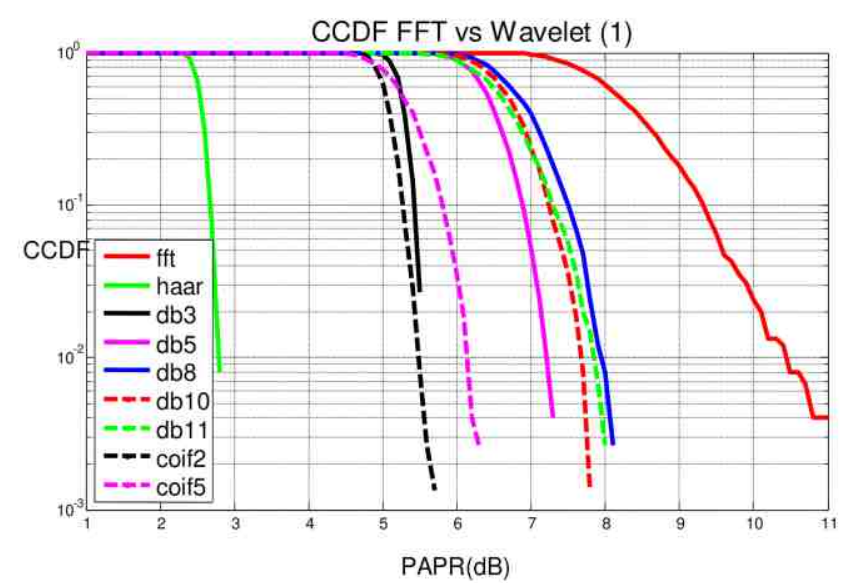

Fig. 10. CCDF FFT vs Wavelet (i)



Fig. 11. CCDF FFT vs Wavelet (ii) 
Table 2. FFT vs Wavelet

\begin{tabular}{|c|c|c|c|}
\hline \multirow{2}{*}{ Transform } & \multicolumn{2}{|c|}{ Eb/No (dB) } & \multirow{2}{*}{ PAPR(dB) } \\
\cline { 2 - 3 } & $\mathbf{F d = 1 0 H z}$ & $\mathbf{F d = 9 7 H z}$ & \\
\hline FFT & 21.794 & 24.423 & 9.316 \\
\hline Haar & 17.175 & 18.178 & 2.68 \\
\hline db3 & 18.392 & 18.539 & 5.42 \\
\hline db5 & 18.934 & 19.941 & 6.883 \\
\hline db8 & 18.872 & 19.628 & 7.503 \\
\hline db10 & 20.15 & 20.9 & 7.242 \\
\hline db11 & 21.42 & 22.48 & 7.296 \\
\hline sym2 & 18.21 & 18.48 & 5.394 \\
\hline sym3 & 18.61 & 18.85 & 5.421 \\
\hline sym4 & 18.99 & 19.46 & 5.132 \\
\hline sym7 & 18.59 & 19.35 & 5.471 \\
\hline sym8 & 19.08 & 19.47 & 5.629 \\
\hline sym9 & 19.56 & 19.8 & 6.188 \\
\hline coif2 & 18.53 & 18.56 & 5.269 \\
\hline coif5 & 19.07 & 20.18 & 5.809 \\
\hline bior1.1 & 17.93 & 18.16 & 2.68 \\
\hline bior6.8 & 19.18 & 19.94 & 5.718 \\
\hline rbio1.1 & 17.69 & 18.11 & 2.68 \\
\hline rbio6.8 & 19.23 & 20.15 & 5.523 \\
\hline
\end{tabular}

\subsection{Comparison Classical and Smooth Clipping}

From Figure 14, simulation with $10 \mathrm{~Hz}$ Doppler shift and $\mathrm{CR}=1, \mathrm{~Eb} / \mathrm{No}$ for FFT at BER $10^{-4}$ with classical clipping $25.861 \mathrm{~dB}$ is better than smooth clipping $29.652 \mathrm{~dB}$. Meanwhile for wavelet based OFDM, example db10, classical clipping around $22.08 \mathrm{~dB}$ and smooth clipping around $24.19 \mathrm{~dB}$. In average BER degradation from clipping process for all filter wavelet and Fourier with classical cliping $5.77 \%$ degradation is better than smooth clipping $11.32 \%$ degradation. This is due to when $r$ signal at condition greater threshold $A$, so signal clipped with amplitude $A$ level in classical clipping. Meanwhile in smooth clipping, when ${ }_{r>\frac{3}{2} A}$, signal clipped with amplitude $A$ level. But when $r \leq \frac{3}{2} A$, signal still clipped with amplitude $r-\frac{1}{b} r^{3}$ level.

From Figure 15, PAPR when clipped with classical clipping $\mathrm{CR}=1$ reviewed in $\mathrm{CCDF}$ at $10^{-1}$ for FFT around $3.453 \mathrm{~dB}$ compared with smooth clipping around $4.113 \mathrm{~dB}$. Meanwhile wavelet based OFDM, example dB10, PAPR with classical clipping $3.18 \mathrm{~dB}$ and with smooth clipping around $3.94 \mathrm{~dB}$. In average PAPR classical clipping for all filter wavelet and Fourier around $3.052263 \mathrm{~dB}$ and with smooth clipping around $3.586684 \mathrm{~dB}$.

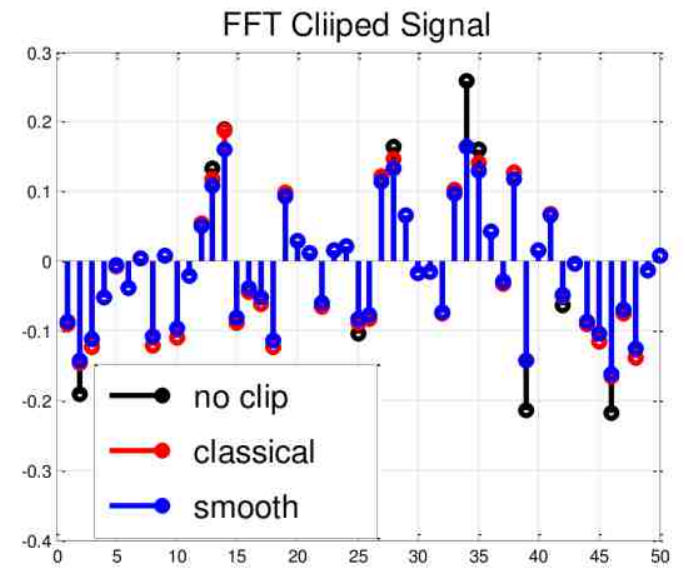

Fig. 12. Clipped Fourier Signal



Fig. 13. Clipped Wavelet Signal 
Journal of Measurements, Electronics, Communications, and Systems (2015) CS0115-02

www.jmecs.org/volla

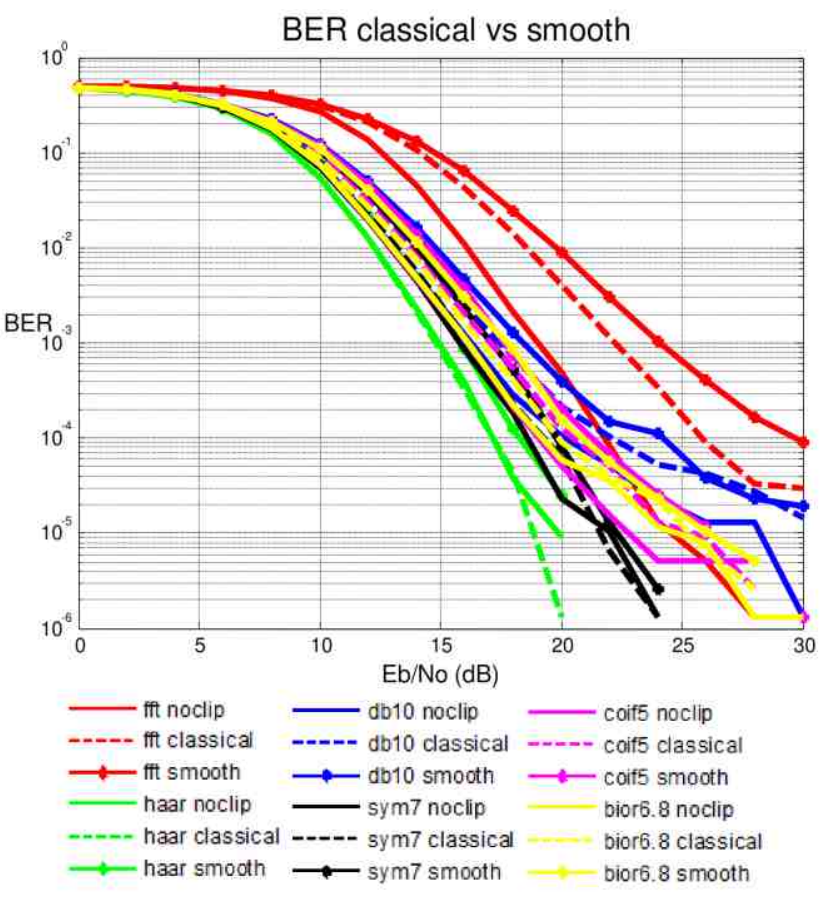

Fig. 14. BER Classical vs Smooth Clipping $C R=1$

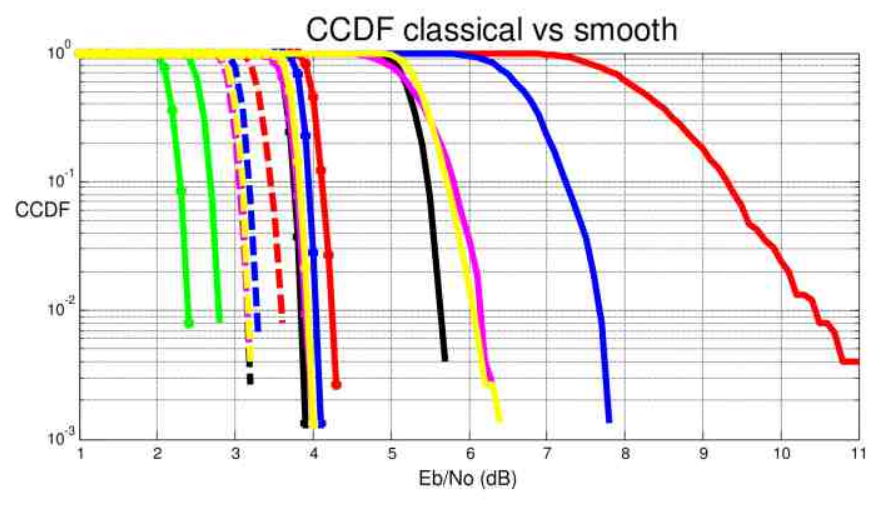

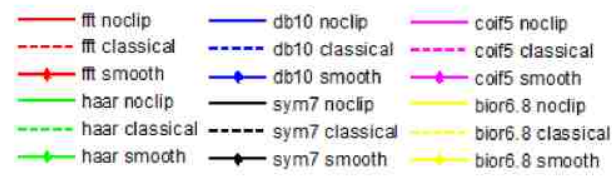

Fig. 15. CCDF Classical vs Smooth Clip $C R=1$

But not all wavelet filter have CCDF classical $\mathrm{CR}=1$ better than smooth clipping, because haar bior1.1 and rbio1.1 filter have CCDF smooth clipping smaller than classical clipping. This due to haar, bior1.1 dan rbio1.1 signal not clipped because signal not in condition to clipped when classical clipping.

\subsection{Classical and Smooth Clipping With Any Clipping Ratio}

In this simulation will analyze using classical clipping and smooth clipping any level of Clipping Ratio. $\mathrm{CR}=1,1.2$, and 1.4. Clipping Ratio will set the threshold to determined signal level after clipping based on Eq. (7).

From Figure 16, average EB/No at BER $10^{-4}$ with classical clipping arranged from the smallest are no clip $<\mathrm{CR}=1.4<\mathrm{CR}=1.2<\mathrm{CR}=1$. And from Figure 17 , average PAPR at $\mathrm{CCDF} 10^{-1}$ with classical clipping arranged from the highest no clip $>$ $\mathrm{CR}=1.4>\mathrm{CR}=1.2>\mathrm{CR}=1$.

From Figure 18, average EB/No at BER $10^{-4}$ with smooth clipping arranged from the smallest are no clip $<\mathrm{CR}=1.4<\mathrm{CR}=1.2<\mathrm{CR}=1$. At Figure 19, average PAPR at CCDF $10^{-1}$ with smooth clipping, arranged from the highest, are no clip $>\mathrm{CR}=1.4>$ $\mathrm{CR}=1.2>\mathrm{CR}=1$.

Table 3. Eb/No Classical and Smooth Clipping $\mathrm{CR}=1,1.2,1.4$

\begin{tabular}{|l|r|r|r|r|r|r|r|}
\hline & \multicolumn{1}{|c|}{ no } & \multicolumn{3}{|c|}{ Classical (dB) } & \multicolumn{3}{c|}{ Smooth (dB) } \\
\cline { 3 - 8 } Filter & clip(dB) & CR=1 & CR=1.2 & CR=1.4 & CR=1 & \multicolumn{1}{c|}{ CR=1.2 } & CR=1.4 \\
\hline FFT & 21.794 & 25.861 & 22.617 & 21.955 & 29.652 & 23.475 & 22.552 \\
\hline Haar & 17.175 & 17.239 & 17.202 & 17.183 & 18.286 & 17.61 & 17.39 \\
\hline db10 & 20.15 & 22.08 & 20.2 & 20.24 & 24.19 & 20.66 & 20.36 \\
\hline sym7 & 18.59 & 19.25 & 18.86 & 18.84 & 19.79 & 19.64 & 19.16 \\
\hline coif5 & 19.07 & 20.48 & 20.16 & 20.13 & 21.29 & 20.35 & 20.32 \\
\hline bior6.8 & 19.18 & 19.88 & 19.5 & 19.44 & 20.86 & 20.23 & 19.52 \\
\hline
\end{tabular}

Table 4. CCDF Classical and Smooth Clipping $\mathrm{CR}=1,1.2,1.4$

\begin{tabular}{|l|r|r|r|r|r|r|r|}
\hline & \multicolumn{1}{|c|}{$\begin{array}{c}\text { no } \\
\text { Filter }\end{array}$} & \multicolumn{3}{|c|}{ Classical (dB) } & \multicolumn{3}{c|}{ Smooth (dB) } \\
\cline { 3 - 8 } & clip(dB) & CR=1 & CR=1.2 & CR=1.4 & CR=1 & \multicolumn{1}{c|}{ CR=1.2 } & CR=1.4 \\
\hline FFT & 9.316 & 3.453 & 4.588 & 5.716 & 4.113 & 5.249 & 6.262 \\
\hline Haar & 2.68 & 2.68 & 2.68 & 2.68 & 2.289 & 2.416 & 2.498 \\
\hline db10 & 7.242 & 3.18 & 4.45 & 5.71 & 3.94 & 5.033 & 5.723 \\
\hline sym7 & 5.471 & 3.072 & 4.42 & 5.47 & 3.747 & 4.355 & 4.687 \\
\hline coif5 & 5.809 & 3.052 & 4.402 & 5.61 & 3.781 & 4.498 & 4.885 \\
\hline bior6.8 & 5.718 & 3.1 & 4.397 & 5.6 & 3.818 & 4.505 & 4.858 \\
\hline
\end{tabular}


Kusuma et al. / Journal of Measurements, Electronics, Communications, and Systems (2015) CS0115-02

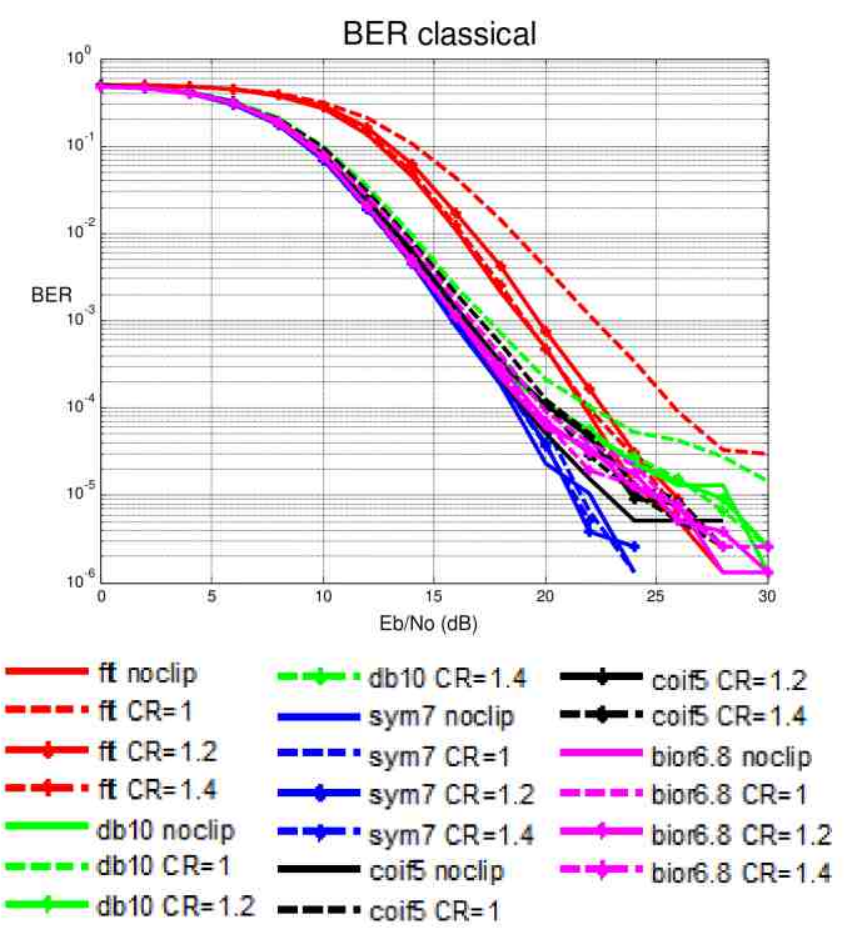

Fig. 16. BER Classical Clipping $(\mathrm{CR}=1,1.2,1.4)$

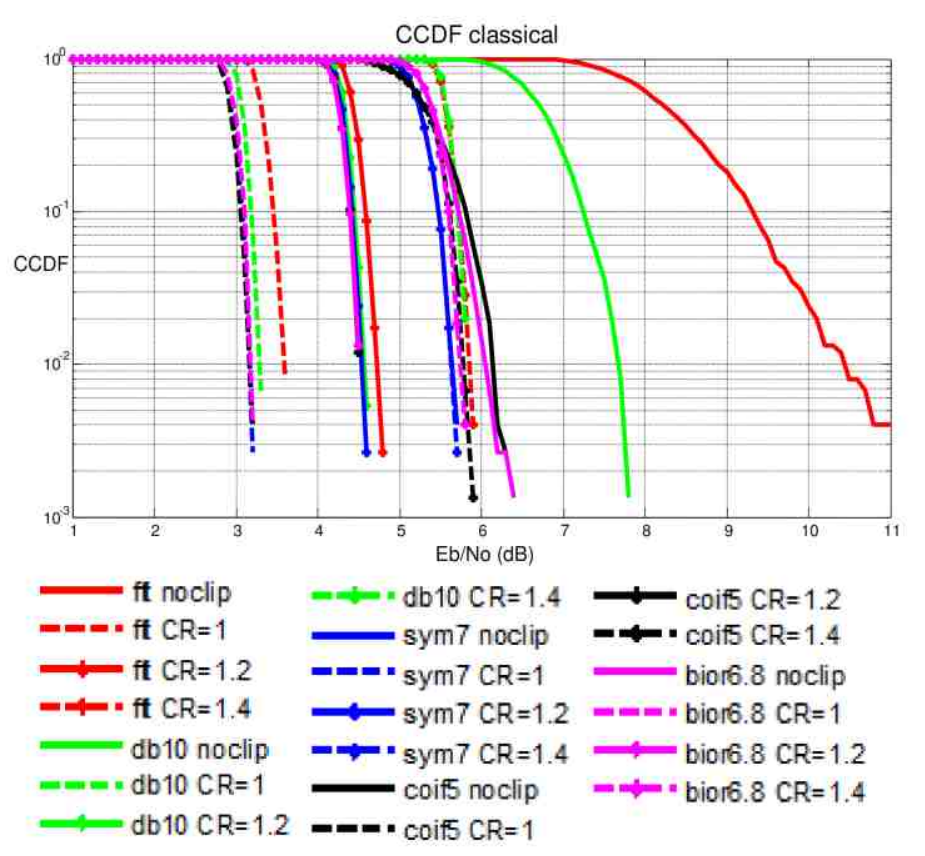

Fig 17. CCDF Classical Clipping ( $\mathrm{CR}=1,1.2,1.4)$

\section{Conclusions}

1. Wavelet based OFDM has a better immunity to noise and Doppler shift than Fourier based.

2. SymN is more resistant to Doppler shift and it is more symmetry.

3. For all wavelet filters, the greater $\mathrm{N}$ orde is, the worse the BER. Among simulated wavelet filters, Haar wavelet has the best PAPR and BER.

4. The performance of BER classical clipping is always better than the smooth clipping in any CR.

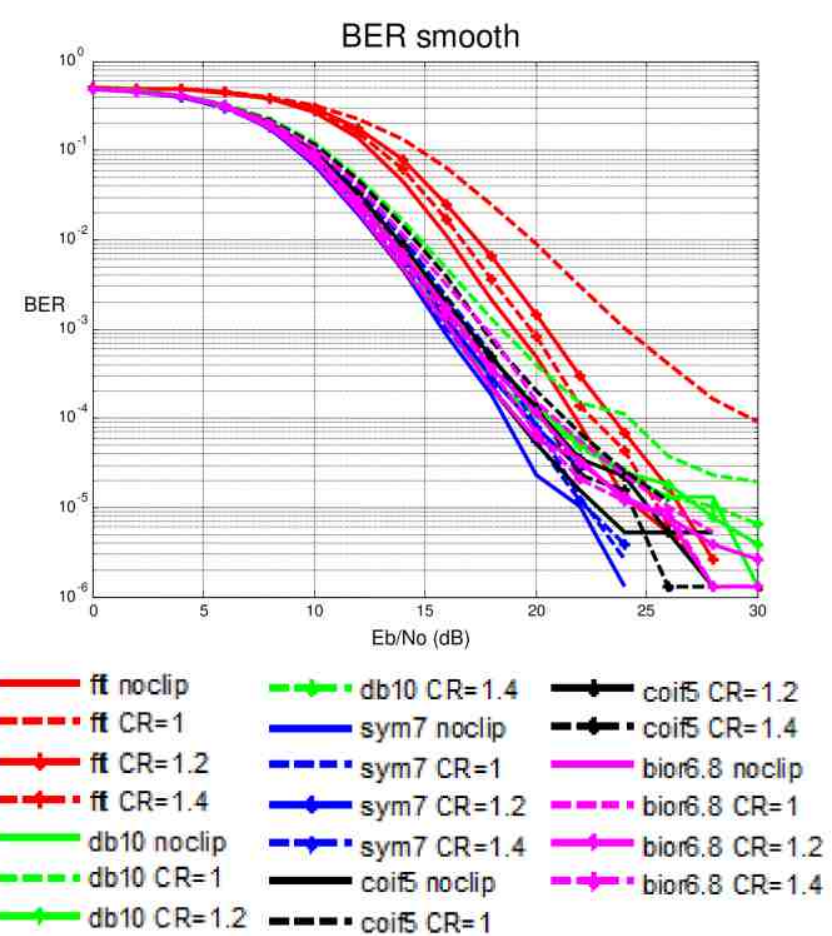

Fig. 18. BER Smooth Clipping $(\mathrm{CR}=1,1.2,1.4)$

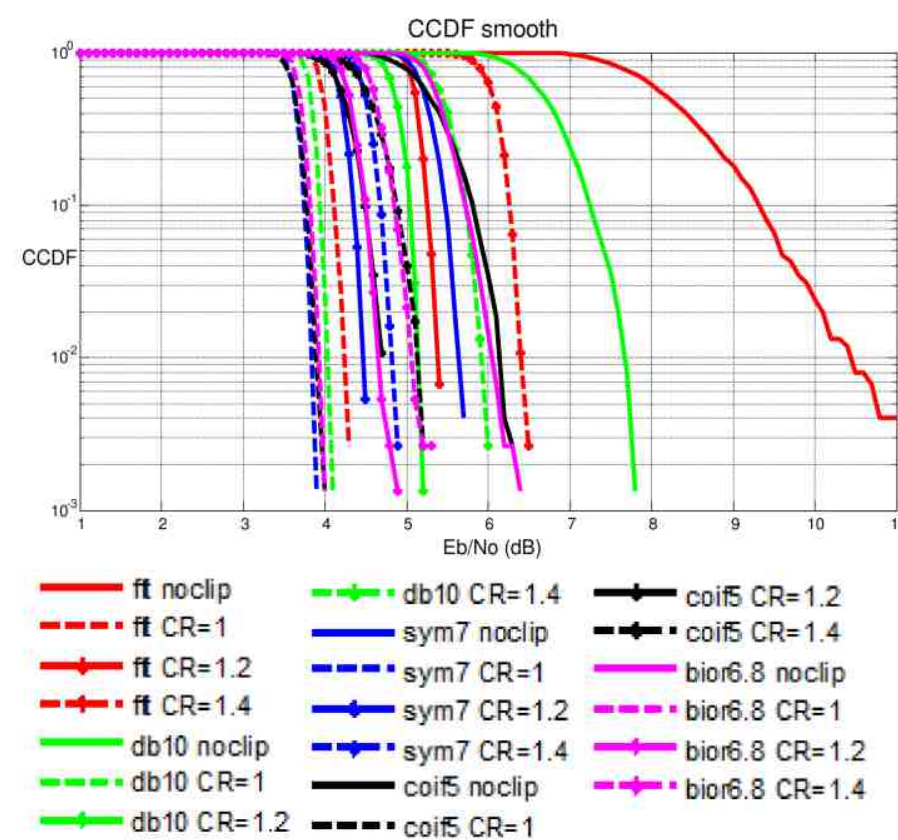

Fig. 19. CCDF Smooth Clipping $(\mathrm{CR}=1,1.2,1.4)$

5. On haar, the bior1.1 and rbiol.1 classical clipping are not clipped in any CR because all signals are not exceeds threshold.

6. Sym 7 with classical clipping and $\mathrm{CR}=1.2$ can be implemented on wavelet based OFDM. Because the difference of BER between Sym7 without any clipping and the one with classical clipping and $\mathrm{CR}=1.2$ is small. Also the $\mathrm{CCDF}$ classical clipping and $\mathrm{CR}=1.2$ better than smooth clipping. 
Kusuma et al. / Journal of Measurements, Electronics, Communications, and Systems (2015) CS0115-02

\section{Acknowledgment}

This work is supported by Research Program of School of Electrical Engineering,Telkom University, Bandung, Indonesia.

*mmardanukusuma@gmail.com

\section{References}

[1] Randy Satria Putra. Reduksi PAPR Pada OFDM Dengan Menggunakan Transformasi Wavelet Dan Teknik Clipping. Universitas Indonesia Depok, 2009.

[2] Abhishek Arun Dash, Vishal Gagrai. OFDM System and PAPR Reduction Techniques in OFDM System. National Institute of Technology, Rourkela. 2010.

[3] Rashmi Mishra, Baibaswata Mohapatra. Performance Evaluation of OFDM System. International Journal of Engineering and Advanced Technology (IJEAT). ISSN: 2249 8958, Volume-1, Issue-3, February 2012.

[4] D. Meenakshi, S. Prabha, N. R. Raajan. Evaluation of BER For Various Fading Channel in DWT Based MIMO-OFDM System. SASTRA University, Tamil Nadu, India - 613401. International Journal of Engineering and Technology (IJET). ISSN : 0975-4024 Vol 5 No 2 Apr-May 2013.

[5] Wahyu Eko Sunarto. Reduksi PAPR Dan Peningkatan Performansi BER Pada Sistem OFDM Menggunakan Teknik Hybrid DCTWavelet Transform Dan Companding $\mu$-Law Transform. Universitas Indonesia Depok, 2010.

[6] Kiki Syahgustina. Simulasi Dan Analisa Kinerja Sistem MIMO OFDM-FDMA Berdasarkan Alokasi Subcarrier. Universitas Indonesia Depok, 2009.

[7] Yudhi Triprasetyo. Analisa Dan Perbandingan Teknik Clipping Untuk Reduksi PAPR Dan Kode Koreksi Error Untuk Performansi BER Pada OFDM. Universitas Indonesia Depok, 2011.

[8] Bestari Dyah Ayu. Simulasi Dan Analisis Pengaruh Modulasi Adaptif Dan STBC-VBLAST Pada Performansi Mobile WiMAX. ITTelkom Bandung, 2013.

[9] Kuldeep Saxena, Naveen Gupta. System Design and Analysis of MIMO STBC -OFDM System with or without Clipping Technique. Institute of Technology \& Management, Gwalior, India. ISSN: 2278-8948, Volume-1, Issue-3, 2012.

[10] Rohit Bodhe, Satish Narkhede, \& Shirish Joshi. Design of Simulink Model For OFDM and Comparison of FFT OFDM and DWT-OFDM. University Of Pune, India. International Journal of Engineering Science and Technology (IJEST). ISSN: 0975-5462 Vol. 4 No.05 May 2012.

[11] Santumon.S.D and B.R. Sujatha. Space-Time Block Coding (STBC) for Wireless Networks. MCE, Karnataka. International Journal of Distributed and Parallel Systems (IJDPS) Vol.3, No.4, July 2012.



Muhamad Mardanu Kusuma was born April 21 $1^{\text {st }} 1988$. He received his Master of Engineering degree from Telkom University, Bandung, Indonesia in 2014. He interest with microwave and optical transmission, MPLS and IP Network. He has about 6 years experience in a telecommunication company. Currently he works as an engineer of E2E Network Surveillance Transmission at PT. Huawei Services. Daily activities are monitor, operation and maintenance optic and microwave radio transmission.

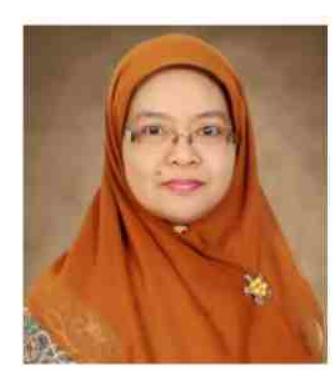

Rina Pudji Astuti is a lecturer in School of Electrical Engineering in Telkom University, Bandung, Indonesia. She finished her undergraduate degree from Electrical Engineering

ITS in 1987, Surabaya. She was graduated from Electrical Engineering Master degree from ITB, Bandung, Indonesia in 1999, and Doctoral degree from Electrical and Informatics Engineering in 2009 from ITB , Bandung, Indonesia. Now she is the Dean of School of Electrical Engineering, Telkom university, Bandung, Indonesia. Her research interests includes Wireless Communication, Multicarrier, Massive MIMO, Space Time Coding, Satellite Communication. She has published a number ofpapers in international journals and conferences.



Dharu Arseno is a lecturer in School of Electrical Engineering in Telkom University, Bandung, Indonesia. $\mathrm{He}$ finished his undergraduate degree and Master degree from Electrical Engineering of Bandung Institute of Technology (ITB) Indonesia in 1995 and 2001. His research interests includes Wireless Communication, Multicell Cooperation and Embedded System 